\title{
Jugar con fuego. Flamenco, juegos de lenguaje y tecnologías de la comunicación
}

\author{
Playing with fire. Flamenco, language games, and communication technology
}

\author{
Antonio Mandly Robles \\ Profesor Titular. Universidad de Sevilla (España). Grupo de Investigación Etnomedia \\ mandly@us.es
}

\author{
Francisco Manuel Llorente Marín \\ Profesor Asociado. Universidad de Málaga (España). Grupo de Investigación Etnomedia \\ llorente@uma.es
}

\begin{abstract}
RESUMEN
La parte maldita de la cultura popular europea, que nadie como Bajtín puso de relieve, se ha dejado sentir en Andalucía a través de los caminos del flamenco. Esta creación histórica de sectores de clases populares andaluzas, que cristaliza en el último tercio del siglo XX como arte popular moderno, resistió a duras penas el intento pequeño burgués de convertir en negocio expresiones de sentimientos y emociones ambiguas e incontrolables, que brotaban entre los intersticios de la ley del más fuerte, hasta llegar a conmover. En una primera lectura abordamos las modulaciones sintácticas procedentes de la queja vocal, la deformación coherente de los significantes, y el aura de carnavalización que les da su frescura. Luego entramos en los contextos etnográficos en que afloran sus juegos del lenguaje y vigencias, que permean en la riqueza léxica y sintáctica de las clases populares andaluzas, entre las que permanecen vivas palabras y expresiones que han muerto en gran parte de España, y hasta en Andalucía. Como veremos, la función social de estas palabras y expresiones, como identidades de resistencia, burlan el orden social de la instrumentalidad gramatical a través del hacer y decir expresivos.
\end{abstract}

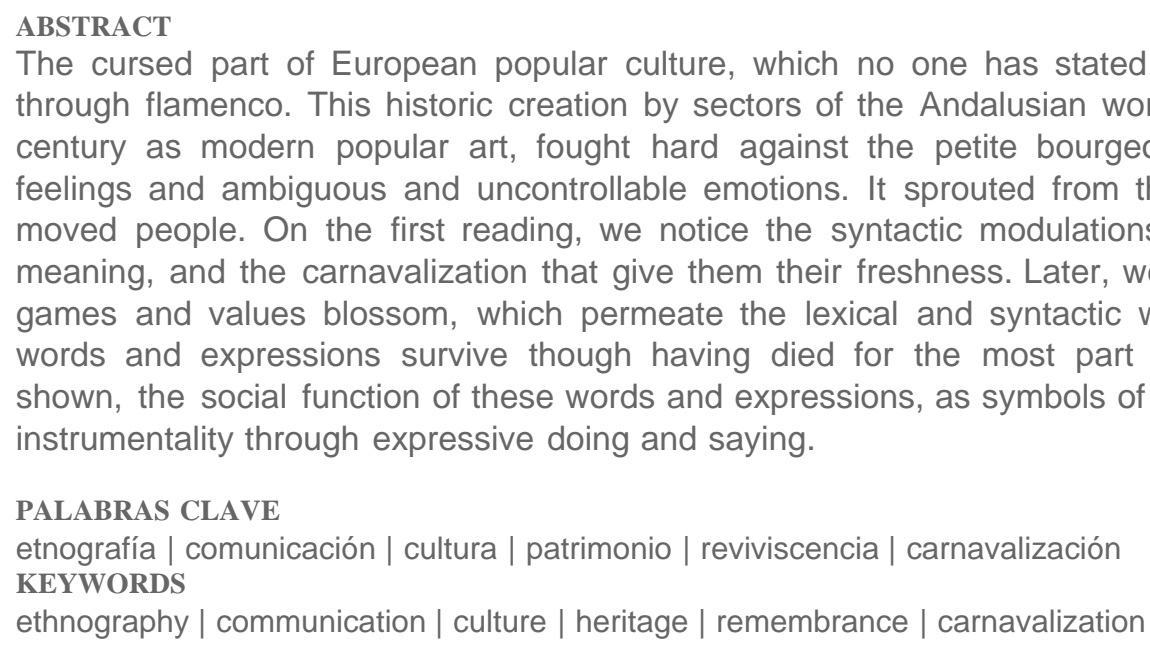
instrumentality through expressive doing and saying.

PALABRAS CLAVE

etnografía | comunicación | cultura | patrimonio | reviviscencia | carnavalización KEYWORDS

ethnography | communication | culture | heritage | remembrance | carnavalization

The cursed part of European popular culture, which no one has stated as well as Batjín, has made itself felt in Andalusia through flamenco. This historic creation by sectors of the Andalusian working class, which formed in the last third of the 20th century as modern popular art, fought hard against the petite bourgeoisie in an attempt to capitalize on the expression of feelings and ambiguous and uncontrollable emotions. It sprouted from the cracks in the law of survival of the fittest until it moved people. On the first reading, we notice the syntactic modulations from the vocal groan, the coherent deformation of meaning, and the carnavalization that give them their freshness. Later, we delve into the ethnographic context where language games and values blossom, which permeate the lexical and syntactic wealth of the Andalusian working class, among whom words and expressions survive though having died for the most part in the rest Spain, and even in Andalusia. As will be shown, the social function of these words and expressions, as symbols of resistance, evade the social order of the grammatical

\section{Introducción}

“Todos los fenómenos estéticos son fenómenos sociales (...). Hay en el hecho estético un elemento de contemplación, de satisfacción más allá de la necesidad inmediata (...). Además lo estético implica siempre una noción de placer sensorial. No existe lo bello sin placer sensorial". Pero además, "el hecho estético está siempre representado en el pensamiento de las personas bajo la forma de juego, de excedente, de lujo" (Mauss 2006: 
Si la historia es siempre presente, se siente especialmente presente cuando se aborda la investigación de la historia de Andalucía desde el análisis de los procesos socioculturales originarios del arte flamenco.

En Los caminos del flamenco. Etnografía, cultura y comunicación en Andalucía -libro transmedia que tomamos como referencia y punto de partida en los aspectos que vamos a desarrollar aquí-, cuando hablábamos de historia, no nos referíamos a una disciplina académica concreta, sino a un conjunto de áreas de conocimiento, particularmente la antropología, que sin perder la orientación de la perspectiva que da la historia, clarifican el instrumento de análisis sobre aspectos del pasado y el presente por la forma de profundizar en ellos, e incluso lo hacen más próximo a causa de la característica fuertemente artesanal de su método, el trabajo de campo etnográfico (durante el cual el antropólogo debe estar in situ, participar como observador en todos los acontecimientos de la vida de la comunidad, no sólo de los trascendentes sino de los aparentemente intrascendentes, beber su agua y su aguardiente, resistir el picante de los guisos y las picaduras de insectos).

La antropología no renuncia en absoluto a la indagación histórica, sino que la retoma y refuerza con métodos y técnicas que no se diferencian notablemente de los utilizados por las ciencias experimentales, aunque su objetivo prioritario es el análisis e interpretación de las culturas, de tal manera que nos lleve a entender las distintas formas en que diferentes personas que componen una comunidad o sociedad se consideran miembros de ella a través de la organización social y económica, de sus creencias, valores, ideología; así como a entender, lo que no es menos importante, qué formas eligen para comunicar estos sentimientos, sea por medio de rituales, fiestas o cualquier otro tipo de expresiones.

Seguimos esta disciplina para el conocimiento y la interpretación de la herencia cultural, y planteamos aquí metodologías de investigación e innovación tecnológica que empezaron a tratarse en Los caminos del flamenco (1). Aquí sugerimos al lector nuevos horizontes en la formulación de hipótesis científicas, desde los análisis de contrapuntos ecológico-culturales y lingüístico-situacionales, que debemos a Lisón, de tal manera que resitúen histórica y funcionalmente el flamenco como juego de lenguaje en sus contextos socioculturales. Vigencias o juegos de lenguaje (2) es como llamamos a las formas de ser o estar en el mundo que no son un asunto privado, ni responden al modelo de los filósofos -en la línea de Descartes- de un yo solitario, individual hegemónico, propio del universo racionalista occidental. El significado de palabras y acciones viene condicionado por un conjunto complejo de presiones sociales complementarias que las hace fluir según status-estrato, etnia, género, edad.

A partir de aquí nuestro objetivo sería comprender mejor la actualidad de este arte popular moderno llamado flamenco, tras el análisis de aspectos muy poco conocidos de su pasado, a través de la evolución de expresiones folclóricas que alcanzaron tal integración social y cultural de punto de partida que cabría situarlas en el plano prístino en que Greimas sitúa la captación estructural que llama etnosemiótica. Así denomina este autor a un objeto semiótico cuya significación viene manifestada por los códigos poético, musical y gesticular a la vez pero "se disuelve en las sociedades llamadas desarrolladas, bajo la forma de discursos disyuntos y autónomos: poesía, música, danza" (Greimas 1980: 195-196). Al mismo tiempo, esta captación estructural de Greimas conlleva el rasgo específico del lenguaje poético, "rasgo que comparte plenamente con las lenguas sagradas de las sociedades arcaicas", y que él denomina "la deformación coherente", que "reside en la distancia, querida por el anunciador, que le separa de la lengua natural que él utiliza para expresarse" (Greimas 1980: 199). Además, tendremos también como objetivo reconocer el pasado interpretando expresiones culturales que hoy lo perpetúan.

Este objetivo tuvo su punto de partida en los análisis de los items arriba citados, a partir del estudio etnográfico publicado por nosotros: "Abriendo caminos. Verdiales, un ritmo mediterráneo de solsticio" (Mandly 2010: 99-143). A partir de él seguimos la metodología de captación estructural que, como apuntamos, Greimas denomina etnosemiótica, en base a sus procesos y resistencias a la disolución, a 
través de la indagación etnográfica de ciertos sentimientos estéticos entendidos como públicos, compartidos, comunes, que se expresan en forma de juego-ritual de carnavalización (3), por ejemplo, durante el ciclo navideño, o las Pascuas, en un entorno como Los Montes de Málaga, y también en barrios urbanos malagueños que la expansión de la ciudad fue absorbiendo a sus expensas, por el norte y el noreste.

El contexto de estas expresiones culturales de baile y rifa, y de coplas que "se levantan" a veces como controversia, se basa en grupos de campesinos fiesteros, que así se llama a los aficionaos que se agrupan para celebrar entre los miembros de su familia extensa y vecinos, bautizos, bodas u otro acontecimiento de regocijo, y que durante el ciclo navideño cobran una autoridad ritual tras formalizar la panda de tontos para recorrer en son de fiesta entre el 25 y 28 de diciembre, lagares y ventas de su territorio o partío.

El objetivo metódico que abre caminos quiere además poner de relieve a través de análisis históricos y funcionales, algunos aspectos de los procesos de construcción de sentido que configuran al flamenco el aura de carnavalización que le ha dado su frescura y capacidad de mestizaje y le ha permitido resistir, como arte popular moderno, los embates del tiempo. Lo hacemos, buceando en las vigencias de grupos étnicos y marginales que fueron alcanzando la gracia por parte de sus contemporáneos, hasta convertir en cultura haceres y decires flameantes, que les llevaron a transformar en fascinante su miseria.

Para cerrar esta introducción, insistimos en que en los procesos de análisis de la cultura como aquí proponemos, es decir, como un sistema en interacción de símbolos, isímbolos que significan!, la cultura no puede ser tratada como una entidad, o algo a lo que puedan atribuirse de manera causal acontecimientos sociales, modos de conducta, instituciones o procesos sociales, sino como un contexto "dentro del cual pueden describirse todos esos fenómenos de manera inteligible" (Geertz 1987: 27).

\section{El contexto de un ámbito estructuralmente marginado}

\section{1. “¡Arrieros somos!”}

En el Siglo de Oro español, el siglo XVI, la movilidad no controlada era un importante factor de desestabilización, como lo fue para el conjunto de la sociedad tradicional. Cualquier caminante era potencialmente peligroso, porque ignoraba los objetivos y las instituciones de la sociedad local, único referente de sus vigencias o valores. Esta es la razón por la que quedó para los arrieros, trajineros y caminantes de todo tipo el estereotipo de la rapiña. Cierto que para estos grupos, las ventas emplazadas al borde de los caminos y en las salidas de los pueblos se convertían en su casa. Aquí reemplazaban al hogar como institución, generaban valores. Era el lugar simbólico del recuerdo, la aventura y el azar; o, lo que es lo mismo, del cante y el juego.

Para el historiador Geremek la desestabilización se presentaba entonces de dos maneras: "una violenta, en forma de bandidaje; otra pasiva, en forma de mendicidad y vagabundeo canalla: la picaresca" (Geremek 1974: 337-375).

Los símbolos hablan el lenguaje de la ecología y nuestra indagación nos llevó hasta un documento etnográfico que arroja luz sobre la situación geográfica de estas ventas emplazadas al borde de los caminos: el Repertorio de todos los caminos de España hasta agora nunca visto... Compuesto por Pero Juan Villuga, valenciano, e impreso en Medina del Campo... en el año 1546. Se trata del primer repertorio de caminos editado en Europa; texto de referencia para los geógrafos y cuyas localizaciones territoriales de ventas, fuentes y lugares han sido establecidas por nosotros. Nuestra etnografía, ayudada por la memoria local, la toponimia y los juegos del lenguaje reveló el contexto y evolución histórica de modalidades de bailes y cantes desde Málaga hasta Sevilla.

A partir de la ciudad de Málaga y sus Montes y la vega del río Guadalhorce, pasando por Álora, Osuna, La Puebla, Marchena, Mairena y aquellas ventas intermedias que sitúa Villuga con precisión (Mandly 
2010: 37-38), nos parece interesante que a partir de los años finales del XIX afloren figuras del cante reconocidas a través de la memoria histórica, pero bajo las que había un tesoro, un magma anónimo, desconocido para la memoria histórica, aunque presente en el recuerdo local a través de la memoria hiponoética (queremos decir, la que está debajo de la visual con que el sujeto controla perfectamente lo que recuerda, o, por decirlo en el contexto de nuestro artículo: la memoria honda).

Hablamos de esta modalidad de memoria de aprendizaje imitativo de actividades, rítmica, inasible, inconcebible, porque lejos de dejarse controlar por el individuo es la que se apodera de tal control y lo hace trizas. Nos referimos a ese tipo de recuerdo que tiene la virtualidad de dilatar o acortar los tiempos cuando uno se sumerge en ellos (García Calvo 1983: 8-14). Por tanto, llamamos hiponoética a aquella memoria inconmensurable que estaba por todo lo hondo de la que en su momento se hizo visible a través de las figuras del Flamenco, y que subyace a expresiones culturales que se manifiestan a través de los juegos del lenguaje, es decir, a través de la intencionalidad y ambigüedad que encontramos reiteradamente en esa cosmovisión marginal que reflejan sus formas de vida (Wittgenstein 1988: 39).

\section{2. ¿Quiénes fueron los flamencos?}

¿Quiénes fueron aquellos grupos abigarrados a quienes denominaron flamencos los escritores románticos? ¿Aquellos que en los bordes del sistema establecido y en las ventas de los caminos asaltaban, reñían, maldecían, jugaban, contaban y cantaban? ¿Qué otros arrojados dejaron su huella en los caminos del flamenco?

\subsubsection{Moriscos y gitanos}

En el valioso documento de 1612 del padre Aznar Cardona, Expulsión justificada de los moriscos españoles, se nos da detallada cuenta de los officios de los moriscos: texedores, sastres, sogueros, esparteños, olleros, çapateros, albeytares, colchoneros, hortelanos, recueros, y revendedores de aceyte, pescado, miel, pasas, açucar, lienços, huevos, gallinas, çapatillos y cosas de lana para los niños. Estos oficios se han mantenido de manera muy estable prácticamente hasta la desaparición de los antiguos gremios, avanzado el siglo XX, y nos dan luz, a través de sus roles, sobre la identidad de los oficiantes o protagonistas del mestizaje de los cantes gitanos y castellanos en las ventas de que hablan Mairena y Molina en Mundo y formas del cante flamenco: "Mientras que los escenarios estrictamente camperos son propios del cante andaluz, la venta congrega profesionales y semiprofesionales, entre los que abundan cultivadores del cante gitano. En la venta siempre alternaron ambos cantes, influyéndose mutuamente" (Mairena y Molina 1964: 148-149).

Los historiadores nos documentan sobre aspectos clave para entender este abigarramiento, y la etnicidad de los arrieros gitanos y sus primos que los acompañaban ya en calidad de profesionales o semiprofesionales del cante en las primeras décadas del siglo XX. Por ejemplo, a través de la herencia gitana de antiguos hábitat moriscos como las Cuevas de Guadix o el barrio de Santiago de Jerez, ocupados por los que entonces fueron expulsados de Granada. Es significativo conocer que aquellos lugares y enclaves donde hubo una mayor población morisca fueran precisamente en los que se asentó el mayor número de gitanos: el Albaycín, Triana, Lebrija, Marchena, Utrera, Jerez -donde el cabildo se hizo eco el 31 de marzo de 1579 de protestas del vecindario "por haber mucha cantidad de esa gente morisca granadina" (sic)-. Y es que no todos los moriscos asentados en territorios españoles se fueron, ni mucho menos, sino que se escabulleron entre esas "bandas errantes, perseguidas con saña, pero sobre las cuales no pesa el anatema de la expulsión y de la muerte. Son los gitanos, errabundos hermanos de todos los perseguidos" (Blas Infante 1980: 162-163, Domínguez Ortiz y Vincent 1978: 264). Si no, ¿cómo es posible que aquella pequeña tropa llegada a mediados del siglo XV a cuyo frente marchaba el conde Tomás, ya entrado el XVIII constituía una población gitana tan numerosa que Fernando VI no encontró sitio para internarlos a todos en los arsenales de Cádiz y Cartagena? ¿Por qué esa "aglomeración constatable" desde principios del siglo XVIII en Andalucía y muy particularmente en Sevilla de la que habla la historiadora María Helena Sánchez? (Sánchez 1976). 
Desde el núcleo del proceso de mestizaje, Blas Infante nos invitó a reflexionar en Orígenes de lo flamenco y secretos del cante jondo por qué los gitanos de Andalucía constituyen el pueblo gitano más numeroso de la Tierra: “¿Lo comprendéis ahora?” (1980: 166).

Por todo ello cuando hablamos de cante gitano no podemos pasar por alto la etnicidad de estos gitanos andaluces, sus juegos de lenguaje, sus formas de vida. A los treinta años del decreto de expulsión de los moriscos aparecen referencias de gitanos labradores. En el expediente de concesión de vecindad a los Contreras, en 1747, se dice que "se mantenían quietos en las labores del campo", y en otro expediente se hace mención a la familia gitana de los Gómez "como los mayores labradores del lugar" (Sánchez 1976).

\subsubsection{Los ciegos o de cómo la realidad no es todo lo que hay}

Andariegos de los caminos que nos interesan especialmente fueron los ciegos, que al igual que los frailes mendicantes hicieron virtud de sus prácticas de la mendicidad, hasta consagrarse como una institución cultural heredera de los juglares medievales. Eran "intérpretes de romances, sermones, poesías, tonadillas y otros cantes propios del ambiente popular, además de autores o distribuidores de una peculiar literatura y poesía, los pliegos de cordel, la voz del pueblo" (Steingress 1993: 264).

Estébanez Calderón en 1847 se entusiasmaba cuando oía tañer y cantar la tonada de la zarabanda, "pura y primitivamente resucitada por estos trovadores de esquina (sic) que por no ver el tanto que quieren, se suelen llamar ciegos" (Estébanez Calderón 1985: 83). ¿Qué era esta zarabanda, que entusiasmó a nuestro informante privilegiado Estébanez Calderón? "Era una danza cantada alegre y lasciva, que tuvo su auge en España a finales del siglo XVI, con textos de carácter libre versificados según un esquema preciso (el zéjel) y con un tono propio en modo de sol y en ritmo sesquiáltero, conservado en cantidad de compilaciones del siglo XVII", nos dice Daniel Devoto (1965) gran musicólogo latinoamericano desaparecido en 2007: "Zarabanda ven ventura/ Zarabanda ven y dura/ El criador es ya criatura/ Zarabanda ven y dura...". "Con el tiempo cambió de carácter y se convirtió progresivamente en la danza lenta que todos conocemos". Asegura Devoto, poniéndonos en la pista de la tonada que oyó tañer y cantar a Estébanez Calderón (Devoto 1965) (4).

La vieja institución cultural de los ciegos, con las mismas estrategias de mendicidad de los frailes, y aprovechando además las legislaciones liberales del siglo XIX que habían debilitado en extremo a los frailes en sus tradicionales ejercicios, encontraron la ocasión de vivir de sus tácticas: la palabra y la música. Aunque muy a menudo desengañaran a la feligresía con sus oraciones y falsas manifestaciones de piedad. Para Julio Caro Baroja, hasta la palabra excesivamente chocarrera de estos ciegos era palabra piadosa, religiosa con frecuencia, porque la religión ha sido cosa popular hasta muy entrado el siglo XIX (Caro Baroja 1978).

Diego de Valencina, el fraile capuchino autor de una monumental historia de la saeta en 1948 se veía obligado a reconocer como elemento público y compartido, cómo coplas burlescas se entremezclan a mediados del siglo XX en las procesiones de Semana Santa con las "lindas saetas" (Valencina 1948: 40). En esta línea de análisis la etnografía de Demetrio Brisset (2010) sobre las actuales saetas borrachunas de Lucena, nos muestra la intencionalidad y ambigüedad con que se entremezclan igualmente expresiones sagradas y profanas en las juntas cuaresmales de la Santería cordobesa. Se trata de reuniones en los locales de la hermandad de los miembros de cada santería en las que el cuadrillero y el manijero, es decir, los miembros con estatus más relevante, están llamados a invitar a comer "a fin de marcar por estaturas, distribuir las funciones, y en definitiva prepararse para el día más significativo del año que está a punto de llegar" (Brisset 2010). Desde luego no es agua lo que allí se bebe, mientras en medio del regocijo cuaresmal se improvisan trovos de controversia que se alternan con antiguos versos bíblicos en forma de diálogo, versos que deben ser cantados en todo caso. "La ausencia de mujeres en las juntas y el ritual que debe mantener en todo momento la copa medio llena, permite que se pueda llegar a ciertas cotas de desenfreno verbal en la controversia" (Brisset 2010), que, como es preceptivo en estos usos rituales, lejos de molestar individualmente a los afectados, hermana e identifica al grupo de santeros. 
De hito en hito aparecen en el flamenco vigencias de la genuina religiosidad que fue transmitida por los ciegos de forma viva, ambigua, vapuleada de puertas para fuera por la prensa conservadora de los años sesenta del siglo XIX que pedía una mañana de Semana Santa en Sevilla una carga policial contra ellos en La Campana "¿Y eso se tolera? ¿Es Sevilla un villorrio?", como Marchena, La Puebla o Lucena, sin ir más lejos (Ortiz Nuevo 1998: 33).

Estos juegos de lenguaje afloran también insospechadamente, en los remates por saeta en sus cantes de juerga de cantaores de la Málaga de principios del siglo XX, que hace suyos, por ejemplo, El Piyayo, cantaor local cuyo acento (que ni siquiera consiguió reproducir fielmente Antonio Mairena) es considerado como la quintaesencia del lumpen malagueño (5). O en la muy formal improvisación de la Saeta de La Puebla a petición de sus compradoras de quincallería con que Pepe la Barbarita nos hizo estremecer una cercana tarde de otoño en la calle Morón de La Puebla, cuando manteníamos una larga conversación sobre los caminos del flamenco y la recova (6). En la saeta a petición de su fiel clientela, que al oír cantar a Pepe una livianas rematadas por serranas durante nuestra visita abarrotaron su tienda para no perdérselas, el cantaor cambia su postura de coloquio informal y ritualiza con su cuerpo y su voz una situación integrada por los códigos poético, musical y gesticular a la vez.

\subsubsection{La picaresca o cuando la miseria se hace fascinante}

La miseria se hizo definitivamente fascinante en el siglo XVI español, muy particularmente en Sevilla. De ello dan prueba mucho mejor que las informaciones de los textos históricos, las novelas que van al fondo de los sentimientos y que protagonizan aquellos grupos sociales que hacían de la necesidad virtud mediante su transformación en artes de toda ralea, idea que pasó a la cultura popular sevillana a través de la expresión simbólica ponderativa y también irónica de "artista", que define localmente a quienes son capaces de buscarse la vida sin necesidad de realizar un trabajo reglado.

Por el puerto de Sevilla entraba todo el oro y la plata del Mundo Nuevo, y salía después de haber circulado por las manos de comerciantes, asentados en calles cercanas a la Casa de la Contratación, de cuya gesta queda hoy el recuerdo: alemanes, placentines, francos. La ciudad más rica de las Españas resultaba muy atractiva para otro tipo de hampa que no dejaba su nombre en las calles sino en el papel impreso del libro. Guzmán de Alfarache parte de Sevilla al igual que don Pablo El Buscón. Rincón y Cortado abandonan su secarral manchego para jugárselas en los caminos y ventas, recalar en Sevilla y conseguir entrar como Dios manda en el gremio o cofradía del patio de Monipodio.

En el último cuarto del siglo XVI Cervantes había tenido ocasión de pasar varias noches en la Venta del Río Blanco en su tarea de recaudador de tributos, y ya en Sevilla otras más en La Alfalfa y la Cárcel Real. Allí aprendió a conocer la vida social, económica y cultural, y la estructura social contemporánea que reflejan hoy los valores culturales en Andalucía: conseguir honores o prestigio social derrochando generosamente favores clientelares entre los cofrades propios y vapuleando a los ajenos. También aprendió a ver el mundo con la máscara simbólica de la carnavalización, que enseña que nadie es más que nadie en el terreno del juego profundo y sin más allá, que emerge desde lo hondo del deseo, esto es, en la fiesta. Fiesta, así se denomina a tal contexto de situación en la literatura universal. Por esto en la fiesta cada expresión dice lo que dice, y además más y otra cosa. Y por eso en su literatura cada palabra dice lo que dice y también más y otra cosa.

Rinconete y Cortadillo apareció publicada en 1613, aunque es ya citada en la edición del Quijote de 1605. De ella queremos glosar un fragmento densamente significativo para comprender el prístino sentido musical, común y anti-elitista donde se cuece el contexto de comunicación expresiva del flamenco, con la aparición de instrumentos que la carencia y la querencia de la cultura transforman musicales: el son de la escoba que concierta con el del chapín y con el ligero repiqueteo de las tejoletas, la forma increíble con que Monipodio logra poner fin a una gran trifulca en su patio, convirtiendo en expresivos utensilios instrumentales del medio donde habita, como un chapín o una escoba. Él mismo rompe un plato que encuentra a mano para formalizar el repiqueteo de las tejoletas, tal como hemos visto repetidamente en nuestros días en veladas de flamenco en Vélez Málaga, donde ladrillos de barro apilados en el contenedor de una obra cercana, se han transformado de golpe y porrazo en rítmicas 
tejoletas por la gracia de las manos que las repiquetean y la inteligencia cultural que sabe situar las prioridades de lo que siente como necesario y lo que siente superfluo (7). La cultura popular andaluza nos enseña que la quiebra de un plato es más necesaria que el plato mismo si con él se contribuye a poner el dedo en la llaga de un ritmo musical que nos cambia de sitio y llega a convertir en amigos a enemigos. Pero Monipodio, además, anticipa una de las reglas del método sociológico: que no son los grupos humanos los que hacen la fiesta, sino la fiesta la que hace a los grupos humanos.

"A esto dijo Monipodio:

-Todos voacedes han hablado como buenos amigos, y como tales amigos se den las manos de amigos.

Diéronselas luego, y la Escalanta, quitándose un chapín, comenzó a tañer en él como en un pandero; la Gananciosa tomó una escoba de palma nueva, que allí se halló acaso, y, rascándola, hizo un son que, aunque ronco y áspero, se concertaba con el del chapín. Monipodio rompió un plato y hizo dos tejoletas, que, puestas entre los dedos y repicadas con gran ligereza, llevaba el contrapunto al chapín y a la escoba.

Espantáronse Rinconete y Cortadillo de la nueva invención de la escoba, porque hasta entonces nunca la habían visto. Conociólo Maniferro y díjoles:

- ¿Admíranse de la escoba? Pues bien hacen, pues música más presta y más sin pesadumbre, ni más barata, no se ha inventado en el mundo (...) tan fácil de deprender, tan mañera de tocar (...).

-Eso creo yo muy bien -respondió Rinconete-, pero escuchemos lo que quieren cantar nuestros músicos, que parece que la Gananciosa ha escupido, señal de que quiere cantar.

Y así era la verdad, porque Monipodio le había rogado que cantase algunas seguidillas de las que se usaban; mas la que comenzó primero fue la Escalanta, y con voz sutil y quebradiza cantó lo siguiente:

-Por un sevillano, rufo a lo valón/ tengo socarrado todo el corazón.

Siguió la Gananciosa cantando:

-Por un morenico de color verde/ ¿cuál es la fogosa que no se pierde?

Y luego Monipodio, dándose gran priesa al meneo de sus tejoletas, dijo:

-Riñen dos amantes, hácese la paz/ si el enojo es grande, es el gusto más.

No quiso la Cariharta pasar su gusto en silencio, porque, tomando otro chapín, se metió en danza, y acompañó a las demás diciendo:

Detente, enojado, no me azotes más;/ que si bien lo miras, a tus carnes das" (8).

Entre las modalidades de voces en el cante, sin duda esta voz sutil y quebradiza es la considerada como más ancestral. Los editores de Rinconete y Cortadillo de Austral, en nota a pie de página a modo de Guía de lectores, observan que "quebradiza se suele llamar alguna vez la voz, para alabar los quiebros, pausas y gorjeos", y el Diccionario de la Real Academia en su acepción figurada tercera que quebradiza "dícese de la voz ágil para hacer quiebros en el cante".

Luis Clemente, prolífico autor de publicaciones de flamenco en los últimos cinco años, propone que los actuales experimentos en torno al flamenco respeten los ritmos ancestrales y anima a "recuperar el sentimiento denso, desgarrado y quebradizo" (9). 


\section{Conclusión}

Cualquier análisis que tenga por objeto seguir la tradición canónica deja en los márgenes evidentes lagunas al inquieto lector, que le indican que la realidad no es todo lo que hay. Hay historias, ensayos y trabajos sociológicos que tratan sobre el flamenco, pero el antropólogo que hace etnografía debe encontrar algo más a través de la densidad de su intencionalidad y ambigüedad. En primera providencia encuentra cómo los grupos marginales que han dejado huella en la historia del flamenco han sido los que mejor se han burlado del poder o lo han desobedecido. Decíamos seguir a Geertz para quien la cultura no es un poder; la cultura no puede ser tratada como una entidad, o algo a lo que puedan atribuirse de manera causal acontecimientos sociales, modos de conducta, instituciones o procesos sociales, sino como un contexto. El contexto de un ámbito estructuralmente marginado y de rituales o fiestas de carnavalización nos remite históricamente a un conjunto de diferentes festejos y formas de tipo carnavalesco, no necesariamente emplazados en el tiempo cronológico estricto previo a la Cuaresma de la iglesia católica, desde cuya ordenación litúrgica se acotó su celebración.

El juego que aviva al flamenco no es un espectáculo, ni tampoco una representación, sino que funciona según sus leyes, mientras permanecen vigentes, aunque se trate de una vida desviada de su orden normal. Eso es lo que selecciona el recuerdo de los aficionaos: una fiesta sin escenario ni división en actores y espectadores, (aunque desde fuera parezca haberla) donde las leyes, prohibiciones y limitaciones que determinan el curso y el orden de la vida normal, se diluyen en la alegría del momento. Así, se conjura todo lo determinado por la desigualdad jerárquica social, y por cualquier otra desigualdad, incluyendo la de edad o posición de poder o prestigio intelectual. Se busca aniquilar toda distancia entre las personas. A veces estallan parodias, y entre quienes no llevan la voz cantante, expresiones simbólicas en la vertiente del insulto y jaleos que no interrumpen el contexto del ritmo o la melodía. En el baile, hasta gestos simbólicos que se dirían obscenidades relacionadas con la fuerza generadora de la tierra y el cuerpo. Siempre, por encima de todo, está el placer de una buena salidita en el hacer o en el decir.

Importa dejar claro que estas categorías no son algo así como ideas abstractas sobre la igualdad y la libertad para usos formales al estilo de la democracia en el poder. Son pensamientos y acciones sensoriales concretas, que se fueron constituyendo durante milenios en colectivos marginales de la cultura popular europea, y que amplios colectivos de Andalucía y España contemporánea sienten como propios, aunque el análisis de alcance medio los tome como incoherencias, deformaciones, sin reparar en lo que pudiera ser una significativa deformación coherente basada en valores culturales.

\section{Notas}

1. En la edición digital que acompaña al libro citado, se recomienda al lector usar también la aplicación interactiva para navegar por sus 33 videos y 18 archivos flash. Ésta abre con una simulación de vuelo sobre el camino del siglo XVI entre Málaga y Sevilla tal como lo documentó Villuga en su Repertorio (1546). Las capas de información cartográfica son propias, más algunas modificadas del Instituto de Cartografía de Andalucía. Hacemos muestra de algunos ejemplos al final de nuestro artículo (figuras 1 , $2,3,4$ y 5$)$.

2. Carmelo Lisón Tolosana en Antropología social en España (1971: 173-226) dedicó un capítulo a tratar estos contrapuntos ecológico-culturales de que hablamos. En Belmonte de los Caballeros (1966: 313, 349) prefería Lisón hablar de vigencias para precisar mejor el significado de los valores y nos animaba a hacer etnografía siguiendo sin tregua el contenido concreto de las conversaciones en relación a las diferentes épocas y faenas agrícolas a lo largo del año, los viajes, las fiestas, la valoración del tiempo, su representación y conceptualización. Wittgenstein argumentó en las Investigaciones filosóficas (1988: 7, 
$23,98,128$ y 334), que el lenguaje es un mundo de relaciones y como tal, se constituye por un mundo de relaciones: de conocimiento, sociales, afectivas, convencionales, de praxis social, de búsqueda de sentido a los deseos, a las esperanzas, a las inquietudes, a los proyectos. Todos ellos tienen un aíre de familia, pero cada uno conserva su idiosincrasia, su carácter específico, su sentido, su uso, o lo que es lo mismo, sus juegos del lenguaje. Aprendemos a usar las palabras, cargadas de valores ya desde el inicio, porque pertenecemos a una cultura, a una forma de vida, a una forma práctica de hacer cosas. En definitiva, hablamos como hablamos por lo que hacemos o desearíamos hacer.

3. Nadie como Mijail Bajtín profundiza en el contexto de este juego profundo de la carnavalización. Su libro La cultura popular en la Edad Media y el Renacimiento. El contexto de François Rabelais, es clave para entender la desobediencia creativa del mundo del flamenco.

4. Nuestro reconocimiento a la Biblioteca del Congreso de Estados Unidos, y a su Sección The Music Division, por el envío de los documentos citados de Daniel Devoto.

5. Si tu boquita fuera un terrón de azúca /toíta la noche estuviera que chupa que chupa/que chupa que chupa/que chupa que chupa./Si tu boquita fueran aceituna verde/toíta la noche estuviera/que muele que muele/que muele que muele, cambian sorprendentemente a este otro remate: La tierra sintió mi muerte/ y las campanas reoblaron/ las sepulturas se abrieron/ los muertos resucitaron.

\section{6. http://www.youtube.com/watch?v=pW5FClck1yc\&playnext=1\&list=PL8A3A607CC30BAAA2}

7. "El hecho musical contribuye a intensificar la fuerza con que lo verosímil penetra en la mente del receptor a través del canto, al igual que en otras ocasiones es a través de palabras, ecos, emociones, etc, capaces de dejar una apariencia de verdad que impacte y haga reaccionar al receptor, apelando al recuerdo" (Pastor Comín 2007: 215)

8. Cervantes, Miguel. Rinconete y Cortadillo (1613). Austral Madrid. XVIII edición, noviembre 2011. Edición y Guía de lectura de Antonio Rey Hazas y Florencio Sevilla Arroyo: 200-201.

9. "A finales del siglo XX se puede hablar del 'elemento mestizo cultural', donde lo más valioso se encuentra en los experimentos que respeten los ritmos ancestrales, que son los menos, los degustadores de atrevimiento con lo arraigado. Para hablar de vanguardia habría que recuperar el sentimiento denso, desgarrado y quebradizo cada vez más ausente en el flamenco". Flamenco, un joven de 200 años.

http://www.flamenco-world.com/what/ques.htm

\section{Bibliografía}

Aznar Cardona

1612 Expulsión justificada de los moriscos españoles y suma de las excelencias christianas de nuestro Rey don Felipe, Tercero deste nombre. Huesca.

Bajtín, Mijail

1941 La cultura popular en la Edad Media y en el Renacimiento. Madrid, Alianza, 1990.

1936 Problemas de la poética de Dostoievski. Madrid, Fondo de Cultura Económica, 1986.

Brisset, Demetrio

2010 "Visión antropológica de las sátiras de Loja. Análisis de las fiestas de Granada (8)", Gazeta de Antropología, no 26 (1), art. 13.

http://www.gazeta-antropologia.es/?p=1649 
Caro Baroja, Julio

1978 Las formas complejas de la vida religiosa (Religión, sociedad y carácter en la España de los siglos XVI y XVII). Madrid, Akal.

Cervantes, Miguel

1613 Rinconete y Cortadillo. Austral Madrid. XVIII edición. Edición y Guía de lectura de Antonio Rey Hazas y Florencio Sevilla Arroyo: 200-201, 2011.

Devoto, Daniel

1965 “¿Qué es la zarabanda?” (I, Boletín Interamericano de música, n 45: 8-16.

1966 “¿Qué es la zarabanda?” (II), Boletín Interamericano de música, nº 51: 3-15.

Domínguez Ortiz, Antonio (y Bernard Vincent)

1978 Historia de los moriscos. Vida y tragedia de una minoría. Revista de Occidente, Madrid.

Estébanez Calderón, Serafín

1847 Escenas andaluzas. Madrid, Cátedra, 1985.

García Calvo, Agustín

1983 Historia contra tradición. Tradición contra historia. Madrid, Lucina.

Geremek, Bronislaw

1974 "Criminalité, vagabondage, pauperismo: la marginalité à l'aube des temps modernes", Revue $D$ 'Histoire moderne et contemporaine, tome XXI, juilet-septembre.

Geertz, Clifford

1973 La interpretación de las culturas. Barcelona, Gedisa, 1987.

Greimas, Algirdas Julien

1976 Semiótica y Ciencias Sociales. Madrid, Fragua, 1980.

Infante, Blas

1980 Origen de lo flamenco y secretos del cante jondo. Sevilla, Junta de Andalucía.

Mairena, Antonio (y Ricardo Molina)

1964 Mundo y formas del cante flamenco. Sevilla, Giralda.

Lisón Tolosana, Carmelo

1966 Belmonte de los Caballeros.Oxford, Clarendon Press.

1971 Antropología social en España. Madrid, Siglo XXI de España Editores.

Mandly Robles, Antonio

2010 Los caminos del flamenco. Etnografía, cultura y comunicación en Andalucía. Sevilla, Signatura.

Mauss, Marcel

1947 Manual de etnografía. Buenos Aíres, Fondo de Cultura, 1947.

Ortiz Nuevo, José Luis

1998 Quién me presta una escalera. Sevilla, Signatura,

Pastor Comín, Juan José

2007 Cervantes: Música y Poesía. El hecho musical en el pensamiento lírico cervantino. Vigo, Academia del Hispanismo.

Sánchez Ortega, María Helena

1976 Documentación selecta sobre la situación de los gitanos españoles en el siglo XVIII. Madrid, Editora Nacional. 
Steingress, Gerhard

1993 Sociología del cante flamenco. Jerez, Centro Andaluz de Flamenco.

Valencina, Diego de

1948 Historia de la saeta y los campanilleros. Sevilla, Editorial Católica Española.

Villuga, Pero Juan

1546 Repertorio de todos los caminos de España hasta agora nunca visto...Compuesto por Pero Juan Villuga, valenciano, e impreso en Medina del Campo... Biblioteca Nacional de Madrid. Facsímil R25459.

Wittgenstein, Ludwig

1953 Investigaciones filosóficas. Barcelona, Grijalbo, 1988.

\section{Apéndice documental}

Imagen 1

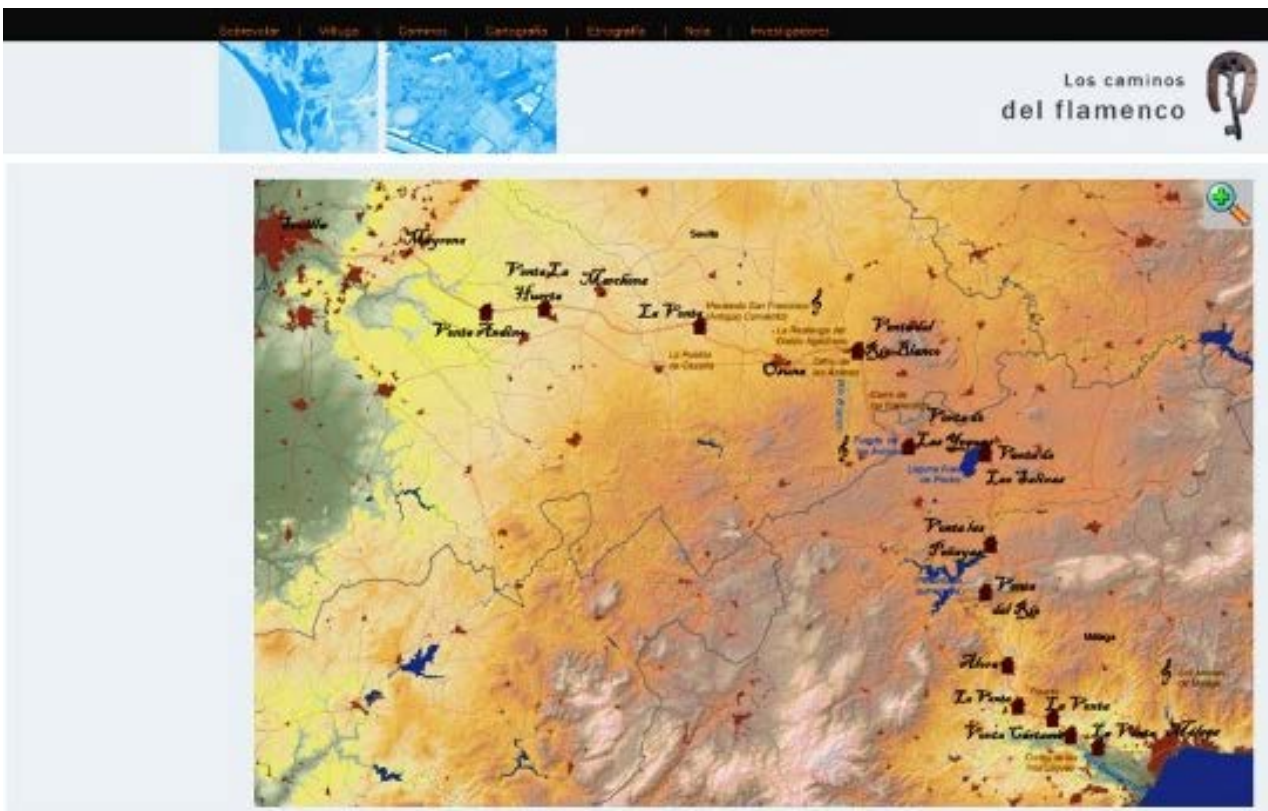

Interfaz de inicio aplicación informática proyecto I+D+I Los Caminos del Flamenco.

Imagen 2 


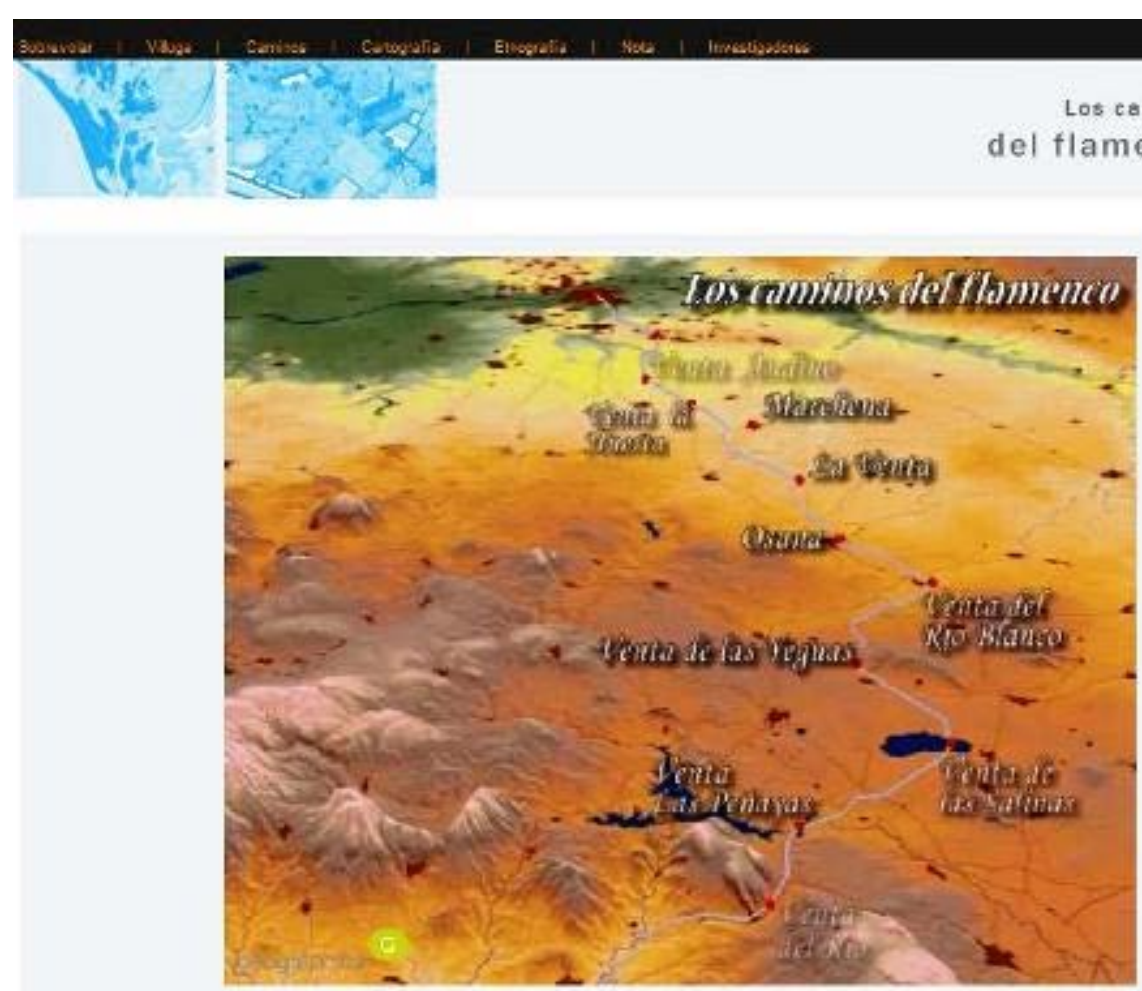

Hay de Nabaga a Sevia.

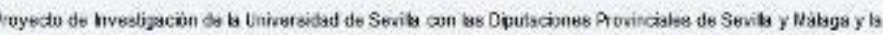

participasibn de a Consejeria de hnoveción, Clencla y Empresa de is Junto de Andeivisa

Simulación de vuelo siguiendo el Repertorio de Villuga (1546).

\section{Imagen 3}

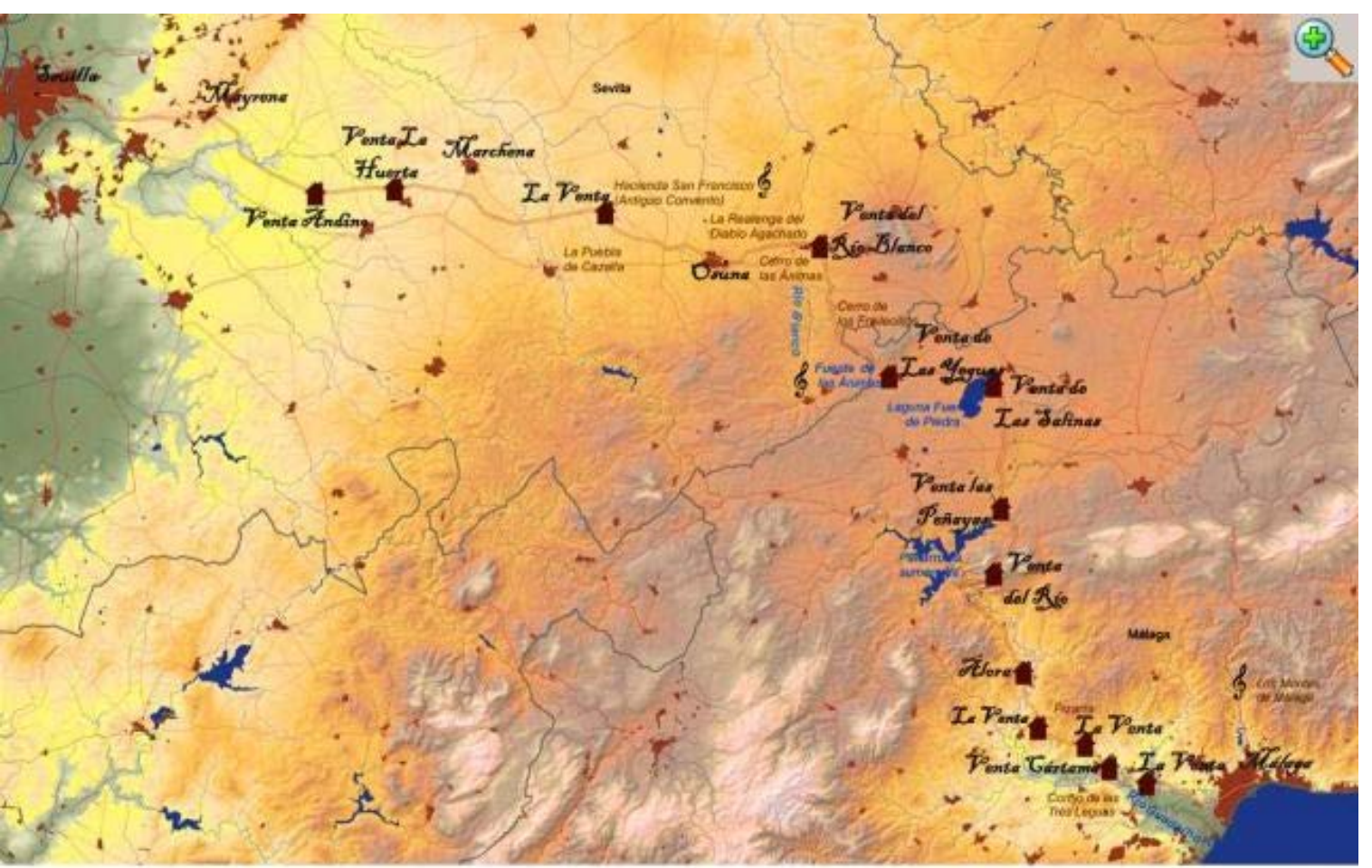




\section{Imagen 4}
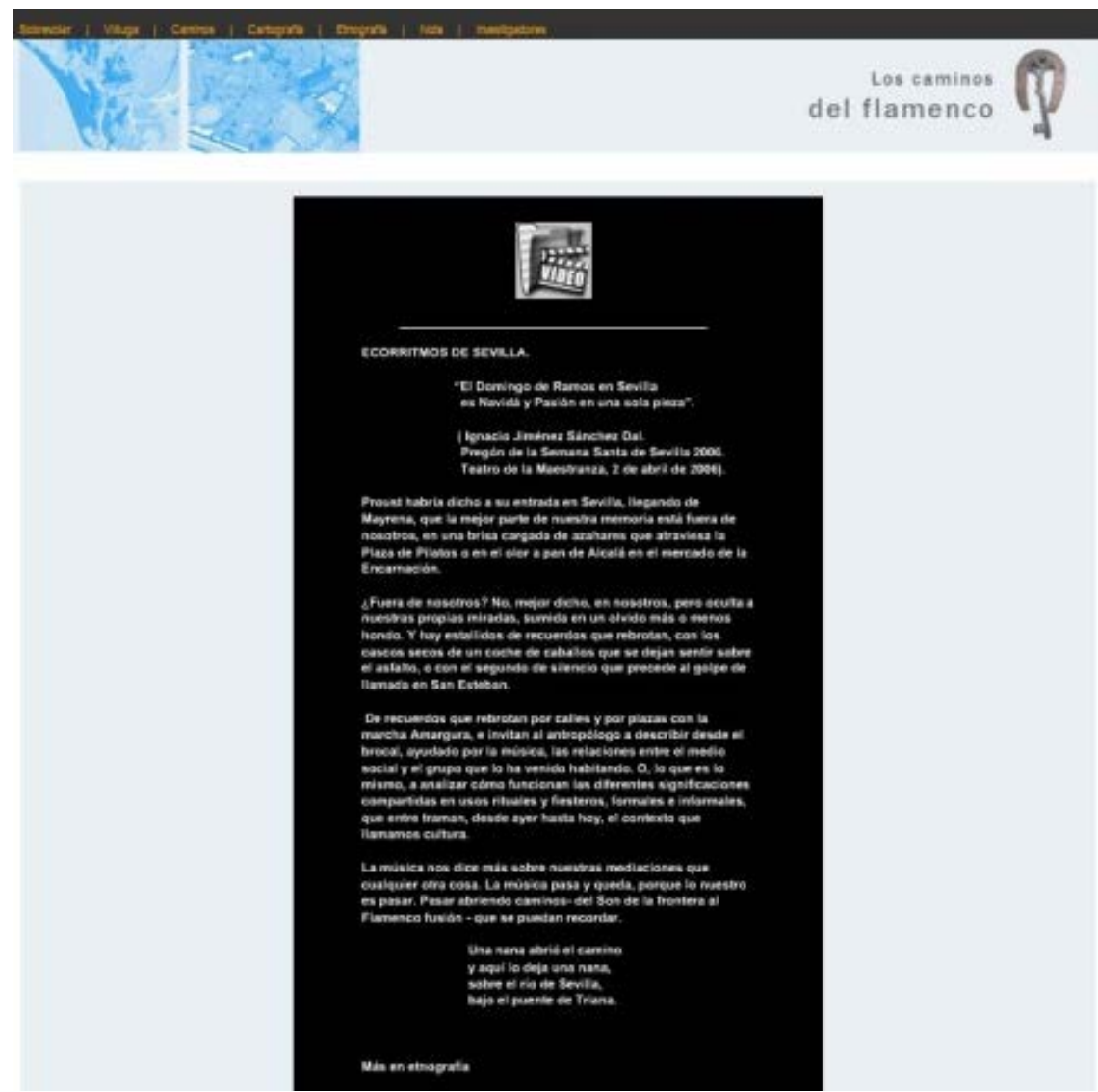

"Ecorritmos de Sevilla". Ejemplo cartela etnográfica de acceso a vídeos.

\section{Imagen 5}



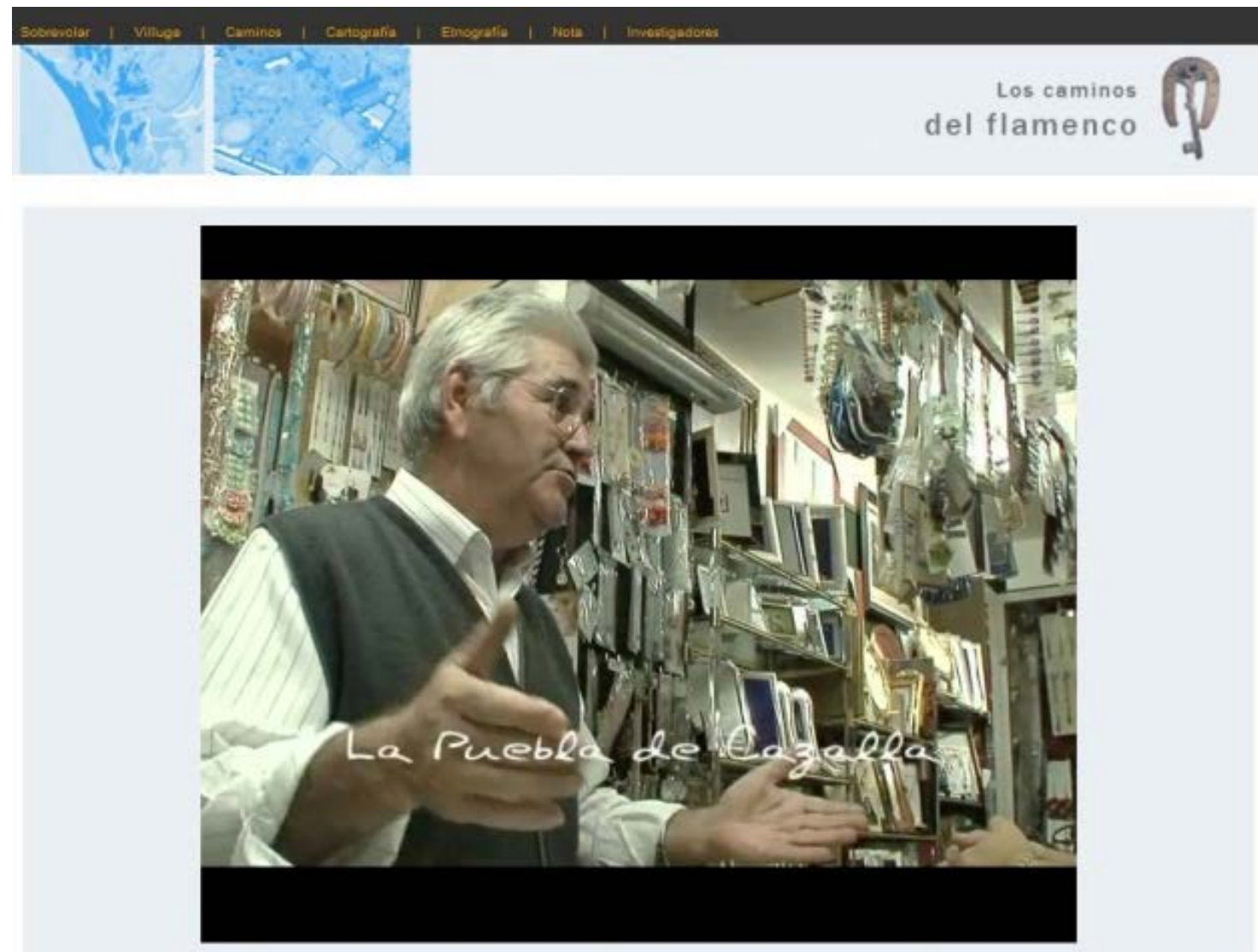

Pepe la barbarita. Ejemplo interfaz reproducción audiovisual en QuickTime.

Imagen 6 


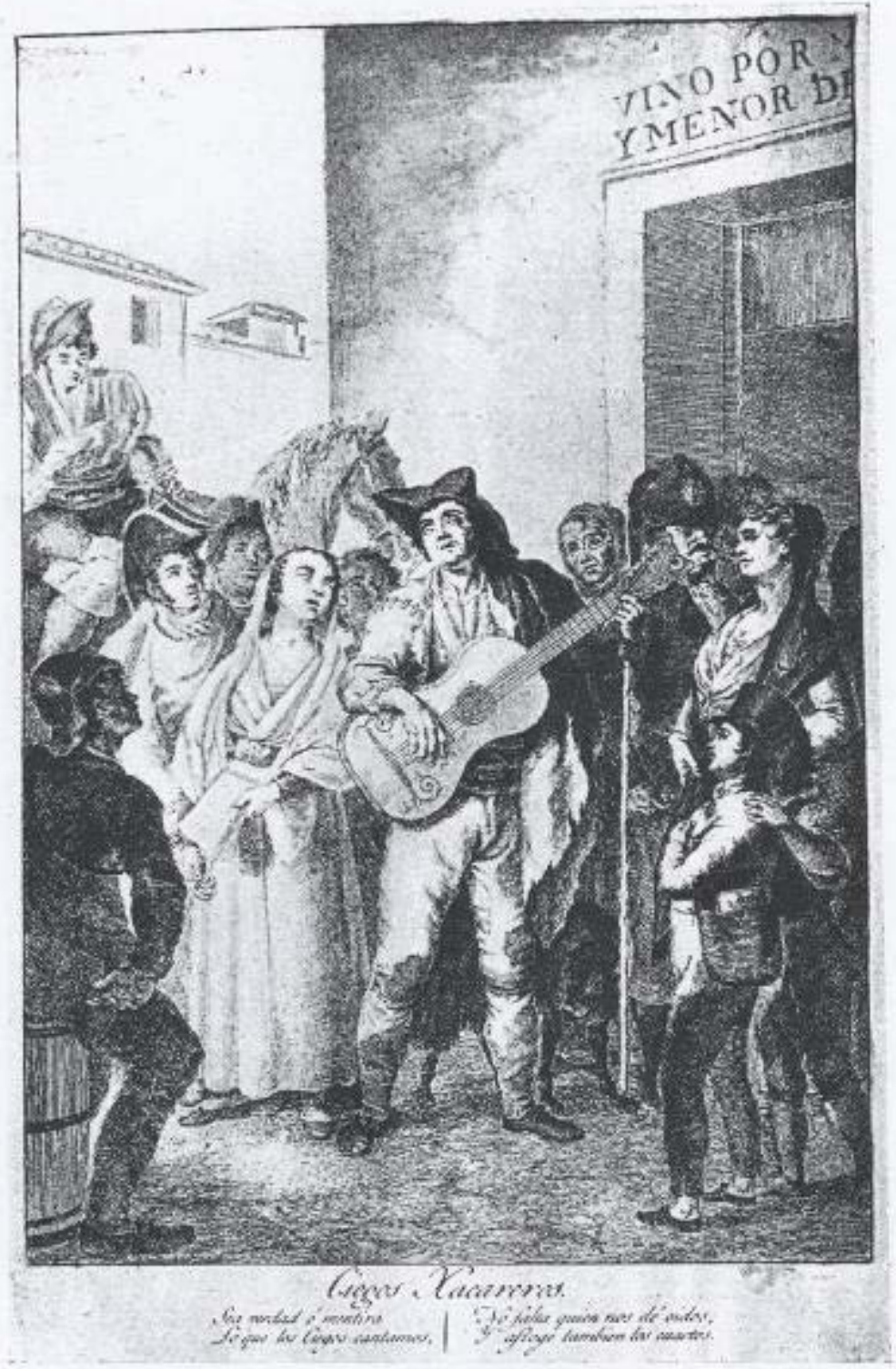

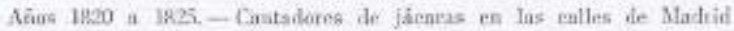

Yinest Utuiripal ale Nadrid

Ciegos Xacareros

Gazeta de Antropología 